\title{
Políticas públicas inclusivas no Brasil e o contexto internacional: diálogos sobre inclusão e deficiência
}

\section{Inclusive public policies in Brazil and the international context: dialogues about inclusion and disability}

\author{
Alexandre Mauricio Fonseca DE AZEVEDO \\ Institut national supérieur de formation et de recherche pour l'éducation des \\ jeunes handicapés et les enseignements adaptés (INS HEA) \\ Maria Lizete Sampaio SOBRAL \\ Institut national supérieur de formation et de recherche pour l'éducation des \\ jeunes handicapés et les enseignements adaptés (INS HEA)
}

\begin{abstract}
RESUMO: Trata este artigo acerca das relações existentes no diálogo que atualmente se trava sobre inclusão e deficiência, fenômenos estes norteadores do debate que destaca aqui o papel das Políticas Públicas, ressaltando-se as políticas internacionais de inclusão educacional no Brasil. Assim, objetivamos analisar o papel dos agentes responsáveis por esse movimento que incrementa a construção e aplicação das políticas públicas na perspectiva da Educação Inclusiva; refletir sobre o fenômeno da inclusão, dentro do panorama atual de discussões, estudos e práticas voltadas para o que se entende como diminuição das desigualdades, e ainda, tratar sobre aspectos específicos a esse processo, considerando propostas que façam parte das diretrizes sócio-inclusivas, definidoras de ações voltadas a tais objetivos sociais. Em relação ao ûltimo caso, evidenciamos no contexto da educação inclusiva no Brasil, a proposta da difusão da Lîngua Brasileira de Sinais nas escolas da educação bâsica, como política de inclusão de pessoas surdas.
\end{abstract}

PALAVRAS-CHAVE: inclusão, deficiência, políticas públicas, educação.

ABSTRACT: This article is about the relationships in the current dialogue about inclusion and disability, phenomena guiding the debate that highlights here the role of Public Policy, emphasizing international policies of educational inclusion in Brazil. Thus, we aimed to analyze the role of agents accountable for this movement that increases the construction and implementation of public policies from the perspective of Inclusive Education; reflect on the inclusion phenomenon within the current situation of discussions, studies and practices focused on what is meant to reduce inequality, and also address specific aspects of this process, considering proposals that are part of the socio-inclusive guidelines, defining actions aimed at such social goals. Regarding the latter case, we noted in the context of inclusive education in Brazil, the proposed dissemination of Brazilian sign language in schools of basic education, the policy of inclusion of deaf people.

KEYWORDS: inclusion, disability, public policy, education.

\section{Introdução}

A ideia de que nos regimes democráticos, no mundo atual, solidificou-se a necessidade de sociabilidade e integração entre indivíduos tem fomentado a luta em 
torno de interesses comuns e pela defesa dos direitos à igualdade para todos ${ }^{1}$. Nessa perspectiva, a adesão por um discurso em favor de oportunidades iguais para todos os homens, e em prol do respeito às diferenças, tem suscitado a abertura de diálogos e a criação de políticas, que procurem garantir o acesso da população, de maneira irrestrita e ampla, aos programas sociais, principalmente, em áreas como saúde e educação.

Os aspectos relacionados às Políticas Internacionais que atuam sob diferentes formas com vistas à integração e inclusão de indivíduos considerados deficientes, em seu meio social, incluem diversos campos do saber e de atuação humana, os quais interferem diretamente na gestão dos recursos humanos e técnicos que se encontram envolvidos como agentes de tais políticas.

Referimos-nos, como campo de opção deste debate, à construção dos ideais sobre os quais se fundamentam o paradigma dos direitos humanos, e de onde assomam os direitos à inclusão social, dentre os quais os direitos das pessoas com deficiência.

Com relação à deficiência, Piovesan $(2009$, p.218) informa ainda que

(...) É sob esta inspiração que, em 13 de dezembro de 2006, foi adotada pela ONU a Convenção sobre os Direitos das Pessoas com Deficiência, nos termos da Assembleia Geral n.61/106. A Convenção entrou em vigor no dia 3 de maio de 2008, mediante o depósito do vigésimo instrumento de ratificação, em conformidade com o artigo 45 do texto. A Convenção surge como resposta da comunidade internacional à longa história de discriminação, exclusão e desumanização das pessoas com deficiência.

Nosso enfoque abrange o processo das políticas educacionais inclusivas, com destaque sobre a legislação vigente em âmbito nacional, e ênfase em algumas ações afirmativas inclusivas em nossa dimensão regional do norte do Brasil, estado do Pará, políticas essas pautadas nos pressupostos universais de uma educação de qualidade para todos, na igualdade de oportunidades e no respeito às diferenças.

É importante ressaltar que o estado do Pará, na região norte do Brasil, apresenta algumas das menores taxas no que se refere ao Índice de Desenvolvimento Humano Municipal (IDHM) ${ }^{2}$ do país, situação associada, de certo modo, ao pouco ou limitado

\footnotetext{
${ }^{11}$ LAMPREIA (2013) ressalta que vale à pena identificar "alguns traços marcantes do mundo atual, do período pós-Guerra Fria, da chamada 'globalização'", dentre eles "[...] crescente convergência no campo dos valores e das práticas políticas - democracia, direitos humanos, posição social da mulher, direitos das crianças e das minorias, meio ambiente, manutenção - e até aprofundamentos, em certos casos - de especificidades nacionais, étnicas, culturais [...]"

${ }_{2}^{2}$ A Organização das Nações Unidas para a Educação, a Ciência e a Cultura (representação da UNESCO no Brasil), divulgou o Índice de Desenvolvimento Humano Municipal (IDHM/2010) no país, conforme
} 
investimento em políticas, sobretudo nas áreas de saúde e educação. Somado a isso, o setor industrial brasileiro concentra-se, em sua maior parte, nas regiões sul e sudeste do país, o que favorece um maior desenvolvimento econômico nessas regiões do territôrio nacional, em detrimento das regiões que acabam se configurando como mais pobres quando tomamos esses parâmetros, como as regiões norte e nordeste.

Consequentemente, a análise incide, também, sobre o papel do Estado ${ }^{3}$, visto que todos esses aspectos, o jurídico, o político, o econômico, o cultural convergem para a possibilidade de concretização ou não de diretrizes políticas e são arrolados como parte de um organismo e movimento que alcançam dimensões globais, já que se encontram sob as vistas também de entidades internacionais.

O imperativo da inclusão, ao ganhar força por meio da mobilização de diferentes grupos sociais, exige do Estado a criação de políticas e ações inclusivas, ao mesmo tempo em que esse imperativo é assumido e produzido pelo Estado. (PROVIN, 2013, p. 104).

\section{Políticas públicas e a atuação dos agentes locais}

Evidenciamos a necessidade de se compreender como operam as múltiplas formas de integração das políticas públicas entre a dimensão internacional e os agentes locais, e igualmente, supomos importante desmistificar esse processo, no contexto do qual, políticas compreendidas como diretrizes absolutas, assumem, algumas vezes, direções diversas em relação aos seus pressupostos fundamentais. Os valores consolidados nos contextos sociais em que são criados podem interferir no desenvolvimento e na concretização das ações pretendidas pelo poder hegemônico, justamente em decorrência dos diversos aspectos que se entrecruzam nesse movimento.

Tal realidade parece-nos visível no país, pois ainda que o Brasil participe como signatário de políticas internacionais que versam sobre a inclusão de deficientes no ambiente escolar ou em seu meio social em geral, inclusive apresentando crescimento

os indicadores anunciados. O Pará apresentou os piores indices nacionais, com os municípios de Melgaço $(0,4180)$ e Chaves $(0,4530)$, ambos situados no arquipélago do Marajó, dentre os 5.565 municipios pesquisados. $\quad<$ http://www.unesco.org/new/pt/brasilia/about-this-office/unesco-resources-inbrazil/statistics/> Em :27/07/2016.

3 “ O Estado é um pacto de dominação e um conjunto de aparatos institucionais auto-reguladores, organizações burocráticas e códigos formais e informais que procuram representar as esferas pública e privada da sociedade. Um papel central do Estado é agir como mediador no contexto da crise do capitalismo, particularmente na contradição entre acumulação e legitimação”. (TORRES, 2001, p. 46) 
no número de alunos deficientes matriculados na educação básica ${ }^{4}$, ainda estamos em processo de adequação para atender a essas propsotas e demandas. Também perceptivel em nossa realidade, sobretudo na região norte do Brasil, é a necessidade de ajustes com vistas à adaptção das escolas quanto aos aspectos físico, estrutural, humano, técnico e cultural, considerando as condições locais/regionais de seus grupos sociais, como já apontamos anteriormente em relação aos índices de desenvolvimento humano - o que configura, de certo modo, a existência de um distanciamento entre os pressupostos das políticas de inclusão e sua efetivação plena.

Isso, quando consideramos que as políticas voltadas para a inclusão ampla do deficiente nas escolas brasileiras são, de certa forma, recentes. $\mathrm{O}$ atendimento a essas diretrizes está em curso, como ocorre com o Decreto 5626 de 22 de dezembro de 2005 , o qual regulamenta a Lei ${ }^{0} 10.436$, de 24 de abril de 2002, que dispõe sobre a Língua Brasileira de Sinais (LIBRAS) e estabelece a inclusão da Língua Brasileira de Sinais (LIBRAS) como disciplina obrigatória, em seu CAPÍTULO II, que trata "DA INCLUSÃO DA LIBRAS COMO DISCIPLINA CURRICULAR”.

Art. $3^{\circ}$ A Libras deve ser inserida como disciplina curricular obrigatória nos cursos de formação de professores para o exercício do magistério, em nível médio e superior, e nos cursos de Fonoaudiologia, de instituições de ensino, públicas e privadas, do sistema federal de ensino e dos sistemas de ensino dos Estados, do Distrito Federal e dos Municípios.

$\S 1^{\underline{0}}$ Todos os cursos de licenciatura, nas diferentes áreas do conhecimento, o curso normal de nível médio, o curso normal superior, o curso de Pedagogia e o curso de Educação Especial são considerados cursos de formação de professores e profissionais da educação para o exercício do magistério.

$\S 2^{\circ}$ A Libras constituir-se-á em disciplina curricular optativa nos demais cursos de educação superior e na educação profissional, a partir de um ano da publicação deste Decreto.

Nesse caso específico, atestamos que o cenário das escolas do sistema básico de ensino encontra-se em construção, com a contratação mais recente de professores formados em cursos de nível superior que os habilite ao ensino da LIBRAS. Isso porque, a grande maioria desses cursos no Brasil só começou a ser ofertada nas

\footnotetext{
${ }^{4}$ Os dados divulgados pelo Ministério da Educação (MEC) no Censo Escolar de 2015 revelam um aumento significativo da matrícula de alunos com deficiência na rede regular de ensino, e indica que em 2014, "mais de 698 mil estudantes especiais estavam matriculados em classes comuns, percentual que representa $93 \%$ em escolas públicas". Além disso, os mesmos dados revelam "que também houve um aumento de $198 \%$ no número de professores com formação em educação especial. Em 2003, eram 3.691 docentes com esse tipo de especialização. Em 2014, esse número chegou a 97.459." Conferir em <http://www.brasil.gov.br/educacao/2015/03/dados-do-censo-escolar-indicam-aumento-de-matriculas-dealunos-com-deficiencia>. Acessado em 27/07/2016.
} 
universidades públicas brasileiras após a obrigatoriedade da oferta, estabelecida pelo mesmo decreto, no ano de 2005. Foi o caso do Curso de Licenciatura em Letras LIBRAS ofertado no Brasil, pela Universidade Federal de Santa Catarina (UFSC), no ano de 2008.

Podemos, assim, constatar que mesmo com a determinação para a inserção da referida disciplina no currículo das escolas, houve, de início, logo após a edição do Decreto 5626/2005, dificuldades para formar equipes de profissionais qualificados na área da inclusão. Somadas a esses fatores, as condições técnicas das escolas, no que se refere à existência de equipamentos, computadores e outros recursos também necessitaram passar por processo de mudanças, destinadas a atender às demandas da inclusão de pessoas com deficência.

Como vemos, essa proposta de diálogo recai sobre a abordagem de diversas categorias, e pode tornar-se bastante ampla, mas a questão em foco, além dos significados constituídos no âmbito das formulações das políticas públicas de inclusão educacional, destaca tanto o modo de reconhecer a diferença, como modos de atuar sobre ela.

Isso quer dizer que as políticas de inclusão de pessoas com deficiência, nas escolas ou em contextos sociais mais gerais, precisam ser pensadas em acordo com suas realidades sócio-históricas, e, portanto, integradas, tanto a uma dimensão mais universal, como também às singularidades que se manifestam como traços simbólicos distintivos, ligados ao mundo particular de cada indivíduo.

\section{As representações da deficiência e as propostas de inclusão}

Assim, a deficiência precisa ser considerada em seu contexto social, quando se proprõem polîticas de inclusão, e isso vale até mesmo para os "padrões de normalidade" que o homem busca criar para si e que vão se modificando na medida em que ele mesmo se vê transformado na sua convivência com o meio social.

Quanto à proposta da inclusão, esses padrões são como temos visto, extremamente diversos, sobretudo quando se pensa a complexidade que envolve essa discussão em diferentes dimensões - social, política, econômica, educacional, linguística - o que nos leva a constatar que é importante instrumentalizar os agentes sociais que promovem a inclusão com a construção de uma legislação de referência, e igualmente 
importante é compreender a abrangência desse fenômeno na perspectiva dos sujeitos que são alvo das propostas de inclusão.

Para isso, consideramos tomar algumas concepções basilares, intrínsecas à noção de inclusão, até mesmo sobre o modo como os agentes da inclusão apropriam-se de um discurso hegemônico para validar sua atuação em acordo com a legislação vigente definidora de diretrizes consideradas essenciais para a inclusão de grupos sociais, que historicamente, se constituíram como minorias marginalizadas em seu meio social.

Tais reflexões implicam a discussão sobre a representação da deficiência, termo que tem sido utilizado para se contrapor em relação ao padrão de normalidade estabelecido segundo uma construção sociocultural, quando nos referimos a pessoas que apresentam restrições no desempenho de determinada capacidade orgânico-fisiológica ou psíquica.

A esse respeito, a Convenção sobre os Direitos das Pessoas com Deficiência, de dezembro de 2006, adotada pela ONU, nos termos da Assembleia Geral n.61/106, assinala a existência do debate sobre as representações suscitadas pelo termo 'deficiência', quando utilizado para indicar diferenças principalmente de ordem psíquica ou orgânica entre os indivíduos, em sociedade.

A própria Convenção reconhece ser a deficiência um conceito em construção, que resulta da interação de pessoas com restrições e barreiras que impedem a plena e efetiva participação na sociedade em igualdade com os demais. Vale dizer, a deficiência deve ser vista como o resultado da interação entre indivíduos e seu meio ambiente e não como algo que reside intrinsicamente no indivíduo (PIOVESAN, 2009, p.218).

No Brasil, o Decreto n ${ }^{\circ} 3.298$, de 20 de dezembro de 1999 que consta na Política Nacional para Integração da Pessoa Portadora de Deficiência, é o que tem se considerado como paradigma à caracterização de uma pessoa com deficiência. $\mathrm{O}$ Decreto, em seu Artigo $3^{\circ}$, define:

I- Deficiência - toda perda ou anormalidade de uma estrutura ou função psicológica, fisiológica ou anatômica que gere incapacidade para o desempenho de atividade, dentro do padrão considerado normal para o ser humano;

II- Deficiência permanente - aquela que ocorreu ou se estabilizou durante um período de tempo suficiente para não permitir recuperação ou ter probabilidade de que se altere, apesar de novos tratamentos; e 
III- Incapacidade - uma redução efetiva e acentuada da capacidade de integração social, com necessidade de equipamentos, adaptações, meios ou recursos especiais para que a pessoa portadora de deficiência possa receber ou transmitir informações necessárias ao seu bem-estar pessoal e ao desempenho de função ou atividade a ser exercida. (BRASIL, 1999).

As definições mencionadas no artigo $3^{\circ}$ do Decreto 3.298/99 representam consenso sobre o que estabelecem alguns documentos oficiais, como parâmetros ou recomendações de organismos internacionais, dentre os quais destacamos a Organização das Nações Unidas (ONU), o Fundo das Nações Unidas para a Infância (UNICEF), a Organização Internacional do Trabalho (OIT) e a Organização Mundial de Saude (OMS).

Ressaltamos, também, a importância da Lei de Inclusão da Pessoa com Deficiência (Estatuto da Pessoa com Deficiência), no 13.146, de 6 de julho de 2015, que no seu Art. $1^{\circ}$, destina-se a "assegurar e a promover, em condições de igualdade, o exercício dos direitos e das liberdades fundamentais por pessoa com deficiência, visando à sua inclusão social e cidadania”, bem como esclarece no seu Art $2^{\circ}$, abaixo descrito, quais critérios considerar para a avaliação das situações de deficiência e de suas especificidades variadas.

Considera-se pessoa com deficiência aquela que tem impedimento de longo prazo de natureza física, mental, intelectual ou sensorial, o qual, em interação com uma ou mais barreiras, pode obstruir sua participação plena e efetiva na sociedade em igualdade de condições com as demais pessoas (BRASIL, 2015).

Segundo Azevedo (2014), o termo deficiência ao qual nos referimos circula particularmente em diferentes áreas do conhecimento, e cada uma delas valida essa noção tomando como referência seus próprios princípios, atrelados a determinados modos de conceber e manifestar os fenômenos do universo social, neste caso o fenômeno da inclusão.

A medicina atribui a si mesma, os procedimentos de normalização do corpo ou do sujeito, tendo como sua co-irmã a psiquiatria, redentora da alma, que é vista hoje como fomentadora de um processo de medicalização de conflitos existenciais sem precedentes na história da saúde mental; a psicopedagogia leva consigo a bandeira da inclusão, promovendo a matrícula incondicional de alunos especiais em classes regulares, o que no mínimo requereria um debate apurado sobre o modo como essas crianças estão sendo recebidas no ensino regular 
(um exemplo são os debates sobre as condições estruturais de nossas escolas, sejam elas físicas ou materiais). Por outro lado, o direito garante a aplicabilidade das políticas públicas de inclusão, pois apresenta as bases jurídicas para implementação de suas diretrizes, promovendo, para os indivíduos considerados deficientes, tratamento igualitário em alguns aspectos, e diferenciado em outros. (AZEVEDO, 2014, p. 41)

Outros autores ampliam essa discussão, acrescentando contribuições ligadas aos significados suscitados em áreas específicas do conhecimento, as quais se ocupam, também, em debater a deficiência, e podem nos permitir pensar a aplicabilidade das diretrizes politicas sobre a inclusão levando em conta, também, os diferentes processos de adaptação. Dentre as contribuições da Sociologia a esses estudos, destacamos a obra intitulada Estigma: notas sobre a manipulação da identidade deteriorada, de Erving Goffman (2012), considerada como referência primordial à compreensão sobre a dinâmica das interações que se travam no ambiente escolar, abordagem reconhecida como "interacionismo simbólico", que se dedica à "análise detalhada da interação pessoa a pessoa em ambientes limitados e em geral de curta duração" (ERIKSEN, T \& NIELSEN, H, 2007, p. 86).

Ao correlacionarmos o termo "inclusão" a diferentes concepções sobre a deficiência, salientamos nessa discussão a construção do paradigma da "educação inclusiva" sobre o qual se assentam as bases de uma proposta de formação humanista, o que significa dizer, voltada para a formação integral do indivíduo, para a construção de uma conduta cidadã e para a defesa dos direitos à igualdade para todos.

\section{Instrumentos das políticas de inclusão}

Conforme tal entendimento, as representações dos discursos nas vozes dos chamados "agentes da inclusão" voltam-se em favor de minorias sociais, encaradas como marginalizadas em seu meio, uma vez que não usufruem plenamente dos direitos civis que lhes deveriam ser garantidos.

Em prol dessas minorias, tem crescido no contexto político internacional o movimento que impulsionado pelas grandes transformações do Direito, vem favorecer os países membros da Organização das Nações Unidas (ONU). O Brasil, como participante, também s ecompromete como a garantia dos direitos à diferença, à singularidade e à subjetividade, propostos na Declaração Universal dos Direitos do Homem, de 1948, documento que passou a servir como parâmetro ao exercício de 
direitos iguais para todas as pessoas e para a efetivação das leis nos países membros da ONU.

Foram as discussões promovidas na área do Direito que influenciaram a criação de novos instrumentos jurídicos ${ }^{5}$, de caráter universal, que alimentariam um sistema de leis capazes de promover e garantir os Direitos humanos (em diferentes áreas do conhecimento). A partir daí, instrumentos normativos internacionais favoreceram a implementação de políticas públicas que se converteram, posteriormente, em programas, projetos e ações na esfera da inclusão.

Destacamos alguns e, dentre eles, citamos, primeiramente, o "Pacto internacional sobre os direitos econômicos, sociais e culturais", adotado pela ONU em 16 de dezembro de 1966, e que trata sobre a proibição da discriminação causada pelo uso da língua. Mais instrumentos constituíram-se como modelos, também, para a implementação das políticas de inclusão, dentre eles o "Programa das Nações Unidas (1982)", com as "Normas Internacionais sobre a readaptação do trabalho (1984)", publicadas pela Organização Internacional do Trabalho (OIT)", a "Declaração de Cartagena das Índias sobre as políticas integrais para as pessoas portadoras de deficiência na região ibero-americana (1992)", a "Declaração de Salamanca (1994)", sobre Princípios e Práticas na Área das Necessidades Educativas e Especiais - que neste contexto merece destaque porque enfatiza a necessidade de os surdos terem acesso à educação através da língua de sinais do seu país.

Outro marco político importante é a Resolução no 48/96 das Nações Unidas, de março de 1994, que ao lançar as "Normas sobre a Igualdade de Oportunidades para Pessoas com Deficiência", aponta para a necessidade da utilização de "língua gestual na educação dos surdos", bem como para a importância de se garantir a presença de intérpretes como mediadores da comunicação, mencionando, que dadas as suas especificidades e necessidades, as crianças surdas constituem um caso especial no que diz respeito à integração de alunos no ensino regular.

No Brasil, os direitos fundamentais concernentes à inclusão de todas as pessoas consideradas deficientes foram redigidos na Constituição Federal de 1988, seguida pela Lei 7.853 de 1989, e pelo Estatuto da Criança e do Adolescente (ECA), estabelecido por

\footnotetext{
${ }^{5}$ Conferir em: Ferreira \& Guimarães (2003, p.86) e Azevedo (2014, pp.52-53).
} 
meio da Lei 8.069/90. Todas essas leis representam a primeira iniciativa concreta, com vistas a implementar um conjunto de medidas jurídicas para a garantia dos direitos de pessoas deficientes, segundo), “em diferentes áreas do conhecimento, na saúde, na área do trabalho, na área de habilitação/reabilitação profissional, na área de assistência social, na área da educação" (FERREIRA \& GUIMARÃES, 2003, p.86).

Definitivamente, podemos dizer que o Brasil fez opção pela construção de um 'Sistema Inclusivo' ao concordar com a Declaração Mundial de Educação para Todos, firmada em Jomtien, na Tailândia, em 1990, que trata, destacadamente, sobre Educação para Todos e a possibilidade de realizar o respeito à diferença.

Outros instrumentos legais também representam tais conquistas, merecendo destaque o decreto 5626/2005, já mencionado anteriormente, que reúne os principais elementos recomendados em diferentes documentos internacionais, publicados pela Organização das Nações Unidas (ONU), Organização Mundial da Saúde (OMS), Fundo das Nações Unidas para a Infância (UNICEF), e pela organização Internacional do Trabalho (OIT). Estas entidades internacionais que também serviram de parâmetro de aplicação da garantia do direito à inclusão do surdo e de pessoas portadoras de outras necessidades educacionais especiais.

Percebemos que todos esses dispositivos políticos possuem alcance diversificado e em diversas direções, na busca de atender às demandas da inclusão de pessoas deficientes da forma mais ampla possível. Por isso, além das políticas públicas que visam garantir a efetivaçao de ações inclusivas estabelecendo parâmetros oficiais para desenvolvê-las, outras realizações somam-se a essas diretrizes, como forma de ampliar e favorecer as diferentes possibilidades de se efetivar uma política pública.

Assim, além da criação dos cursos de graduação pioneiros no Brasil para atender à demanda do ensino de LIBRAS, dentre eles, o Curso de Letras-LIBRAS da Universidade Federal de Santa Catarina (UFSC) em 2006, o Curso de Licenciatura em Letras LIBRAS e Bacharelado em Letras LIBRAS da Universidade Estadual do Pará (UEPA) em 2008, o Curso de Letras LIBRAS e Língua Portuguesa como segunda língua para surdos da Universidade Federal do Pará (UFPA) em 2011, e mais recentemente em 2015, o curso de Licenciatura em Língua de Sinais Brasileira/Português como segunda língua da Universidade de Brasilia (UNB). Registramos em âmbito internacional os acordos firmados entre a Universidade Federal 
do Pará (UFPA) e algumas instituições reconhecidas mundialmente na área da deficiência $^{6}$, tais como o Institut National Supérieur de Formation et de Recherche pour L'Education de Jeunes Handicapés et les Enseignement Adaptés (INS-HEA) e o Instituto Nacional de Jovens Surdos de Paris (INJS), ambos na França.

Todas essas propostas, ações e dispositivos que nos remetem à aplicabilidade das leis, como vimos, reafirmam o direito à igualdade para todos que convivem em sociedade e são imperativos para a efetivação de um modelo de inclusão global pretendido. Por outro lado, como também refletimos, nem sempre essas propostas demonstram reconhecer plenamente as limitações, diferenças e necessidades locais e regionais que existem, principalmente em um pais de dimensões tão grandes como o Brasil, o qual apresenta, também, enorme diversidade cultural. Por isso é preciso exercitar esse tipo de postura, que nos permita uma visão mais ampliada e diversificada em relação ao universo com o qual lidamos, sobretudo quando tratamos com temáticas que evidenciam particularidades da vivência humana como as que aqui levantamos. Senão, estaremos incorrendo em um posicionamento e visão talvez totalitários, que apenas reproduzem a desigualdade no campo da educação, ao invés de buscar diminuíla.

\section{Considerações finais}

Percebemos que uma certa contradição pode residir na relação entre o modo pelo qual as leis são pensadas, a maneira como são aplicadas e o discurso e a atuação dos agentes que circulam e colocam em prática as políticas de educação inclusiva.

Isso porque, talvez, a ideia de inclusão seja uma proposição que serve a diferentes objetivos e interesses, que vão desde ideais humanitários, aparelhamento das instituições que visam ao melhor aprimoramento do Estado e ao atendimento de suas expectativas, como também a interesses individualizantes que se manifestam através da disposição e das ações dos agentes sociais que atuam em um campo historicamente constituído (CHAUVIRÉ \& FONTAINE, 2003, p. 10).

\footnotetext{
${ }^{6}$ As ações que têm integrado tal acordo entre essas Instituições vêm sendo ampliadas no âmbito da UFPA, principalmente e mais precisamente, no âmbito da Faculdade de Letras Estrangeiras Modernas (FALEM), a qual está atrelado o Curso de LIBRAS e Lingua Portuguesa como Segunda Língua para Surdos (LIBRAS e PL2), curso este no qual atuo como professor adjunto desde o ano de 2009.
} 
Temos, então, de um lado, as instituições (públicas ou privadas) consideradas legítimas representantes das políticas educacionais inclusivas, e de outro, o papel dos agentes que atuando no campo profissional da inclusão, se colocam como porta-vozes de uma "minoria excluída", incorporando e manifestando em seu discurso, não somente propostas que refletem suas atitudes, mas também as expectativas do coletivo que eles representam.

Por isso, o campo de interlocução entre essas dimensões distintas que atuam em relação à deficiência e à inclusão deve ser aprofundado na essência existência humana, uma vez que trata não só sobre igualdade entre os homens em seu meio, mas também manifesta as particularidades interessantes entendidas como diferenças, que constitui a própria riqueza da vida social.

\section{Referências}

AZEVEDO, Alexandre Maurício Fonseca de. Crianças especiais na Ilha do Marajó: uma abordagem antropológica / Alexandre Maurício Fonseca de Azevedo, Tese de Doutorado apresentada ao Programa de Pos-graduação em Ciências Sociais (IFCH), da Universidade Federal do Para, sob orientação de Maria Angelica Motta-Maués (2014)

CHAUVIRÉ, Christiane \& FONTAINE, Olivier. Le Vocabulaire de Bourdieu. Paris: Ellipses Édition Marketing S.A, 2003.

ERIKSEN, Thomas Hylland; NIELSEN, Finn Sivert. História da Antropologia. Petrópolis, RJ: Vozes, 2007.

FERREIRA, Maria Elisa Caputo \& GUIMARÃES, Marly. Educação inclusiva. Rio de Janeiro: DP\&A, 2003.

GOFFMAN, Erving. Estigma: notas sobre a manipulação da identidade deteriorada. 4. ed. Rio de Janeiro: LTC, 2012.

LAMPREIA, Luiz Felipe. Política externa do governo FHC: continuidade e renovação. In: O CEBRI e as relações internacionais no Brasil. PAZ, Antonio (Org.). São Paulo: Editora Senac São Paulo, 2013.

PIOVESAN, Flávia. Direitos Humanos e o Direito Constitucional Internacional. São Paulo: Editora Saraiva, 2009.

PROVIN, Priscila. Inclusão na universidade: estratégias para o ensino de "todos" no ensino superior. In: Inclusão e biopolítica. FABRIS, Elí T. HEnn \& KLEIN, Rejane Ramos (Orgs.). Belo Horizonte: Autêntica Editora, 2013. 
TORRES, Carlos Alberto. (Trad. Carlos Almeida Pereira). Democracia, Educação e Multiculturalismo: Dilemas da cidadania em um mundo globalizado. Petrópolis, RJ: Editora Vozes, 2001.

\section{DOCUMENTOS DE REFERÊNCIA NACIONAIS E INTERNACIONAIS}

BRASIL.

Const.

Federal.

http://www.planalto.gov.br/ccivil_03/Constituicao/Constituicao.htm. Acesso em 25/07/2016.

BRASIL. Presidência da República. Casa Civil - Sub Chefia para assuntos jurídicos.

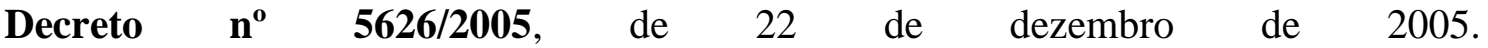
http://www.planalto.gov.br/ccivil_03/_ato2004-2006/2005/decreto/d5626.htm. Acesso em 25/07/2016.

Decreto $\mathbf{N}^{\circ} \mathbf{3 . 2 9 8}$, de 20 de dezembro de 1999. Regulamenta a Lei $\mathrm{n}^{\mathrm{o}}$ 7.853, de 24 de outubro de 1989, dispõe sobre a Política Nacional para a Integração da Pessoa Portadora de Deficiência........ Disponível em: $<$ http://www.planalto.gov.br/ccivil_03/_Ato2015-2018/2015/Lei/L13146.htm >. Acesso em 27/07/2016.

Estatuto da Criança e do Adolescente - ECA. Lei nº 8.069/90 atualizado

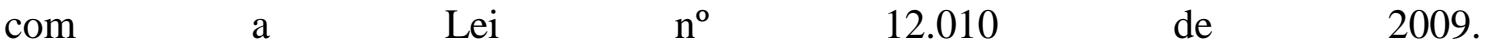

https://www.tjsc.jus.br/infjuv/documentos/ECA_CEIJ/Estatuto. Acesso em 29/07/2016.

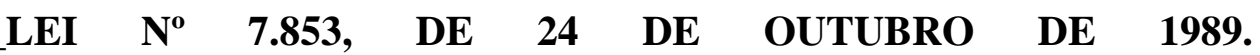
http://www.planalto.gov.br/ccivil_03/leis/L7853.htm. Acesso em 29/07/2016.

Presidência da República. Casa Civil - Sub Chefia para assuntos jurídicos. Lei no 9394, de 20 de dezembro de 1996. Acesso em 27/07/2016.

BRASIL. Lei 13.146, de 6 de julho de 2015, que institui a Lei Brasileira de Inclusão da Pessoa com Deficiência (Estatuto da Pessoa com Deficiência), dispõe sobre a Política Nacional para a Integração da Pessoa Portadora de Deficiência. Disponível em: $<$ http://www.planalto.gov.br /ccivil_03/ decreto/d3298.htm>. Acesso em 27/07/2016.

Ministério da Educação.

<http://www.brasil.gov.br/educacao/2015/03/dados-do-censo-escolar-indicamaumento-de-matriculas-de-alunos-com-deficiencia>. Acesso em 27 de julho de 2016.

NAÇÕES UNIDAS (ONU). Convenção sobre os Direitos das Pessoas com Deficiência, de dezembro de 2006, adotada pela ONU, nos termos da Assembleia Geral n.61/106. https://www.un.org/development/desa/disabilities/ Acesso em 29/07/2016. 
http://www.acnur.org/t3/fileadmin/Documentos/portugues/BD_Legal/Instrumentos_Inte rnacionais/Declaracao_de_Cartagena.pdf?view=1. Acesso em 27/07/2016.

Declaração de Salamanca: Linha de Ação sobre Necessidades Educativas Especiais. Junho de 1994, Espanha. cape.edunet.sp.gov.br/textos/declaracoes/3Declacao_Salamanca.doc. Acesso em 25/07/2016.

Declaração Universal dos Direitos Humanos. Adotada e proclamada pela resolução 217A (III) da Assembleia Geral das Nações Unidas (1948). Disponível em:< http://portal.mj.gov.br/sedh/ct/legis_intern/ddh_bib_inter_universal. htm>. Acesso em 25/07/2016.

Normas Internacionais sobre a readaptação do trabalho (1984). Publicadas pela Organização Internacional do Trabalho (OIT). file:///C://Downloads/Normas_Internacionais_Trab1.pdf. Acesso em 29/07/2016

Comissão das comunidades europeias. Normas sobre a Igualdade de Oportunidades para Pessoas com Deficiência. http://ec.europa.eu/employment_social/soc-prot/disable/com406/406-pt.pdf. Acesso em 28/07/2016.

culturais,16 de dezembro 1966.

Pacto internacional sobre os direitos econômicos, sociais e http://www.unfpa.org.br/Arquivos/pacto_internacional.pdf. Acesso em 28/07/2016.

UNESCO. Declaração Mundial sobre Educação para Todos: satisfação das necessidades básicas de aprendizagem. Jomtien, 1990. http://unesdoc.unesco.org/images/0008/000862/086291 por.pdf. Acesso em 28/07/2016. 